\title{
Elemental Mapping of Nanoscale Structures in the Aberration-Corrected Analytical Electron Microscope
}

\author{
A. Herzing***, I. M. Anderson*, J. K. Edwards***, A. F.Carley***, G. J. Hutchings***, X. Li**, \\ W. Zhang**, C. J. Kiely** \\ * National Institute of Standards and Technology, 100 Bureau Drive, Gaithersburg, MD 20899, USA \\ ** Center for Advanced Materials and Nanotechnology \& Department of Civil and Environmental \\ Engineering, Lehigh University, 5 Packer Ave., Bethlehem, PA 18015, USA \\ *** School of Chemistry, Cardiff University, Main Building, Park Place, Cardiff, CF10 3AT, UK
}

Modern analytical electron microscopes (AEM's) are powerful instruments for the structural and chemical characterization of materials at the nanoscale, and recent developments promise to further enhance their capabilities. Spherical aberration-correctors have made possible the formation of ultrafine electron probes with a total current that is comparable to that in the uncorrected instrument [1], making the aberration-corrected AEM ideally suited for microanalysis at the nanoscale.

In addition, the acquisition of spectrum images in the AEM, whereby an individual spectrum (XEDS or EELS) is acquired at each image pixel of an operator defined image area, can now be routinely performed on many instruments. The highly redundant datasets produced in this fashion lend themselves to post-acquisition data mining and statistical processing, such as principal component analysis (PCA), which can further enhance the quality of AEM microanalytical data $[2,3]$.

These techniques have been employed to characterize several interesting nanoscale structures. For example, the morphological development of bimetallic nanoparticles in a heterogeneous catalyst system as a function of synthesis conditions was monitored via XEDS in an aberration-corrected VG HB603 STEM. The elemental maps presented in Fig. 1 were acquired from a series of $\mathrm{Au}-\mathrm{Pd} / \mathrm{Al}_{2} \mathrm{O}_{3}$ catalysts which were subjected to various heat treatment temperatures and atmospheres [4]. STEMXEDS analysis revealed that the metal particles in this catalyst were altered from homogeneous Au$\mathrm{Pd}$ alloys in the as-synthesized state to Au-rich core/Pd-rich shell particles during calcination due to the preferential migration and oxidation of $\mathrm{Pd}$ at the particle surfaces. Subsequent reduction of the catalyst did not result in re-homogenization of the bimetallic particles, since the majority retained their Pd-rich surfaces. However, a minority of particles exhibited an unexpected morphological inversion, resulting in a Au-rich surface with a Pd-rich core (not shown), which is the favored structure in terms of surface energetics.

Similar techniques were employed to analyze nanoscale zero-valent iron (nZVI) particles. These materials were synthesized via reduction of $\mathrm{FeCl}_{3}$ [5] by $\mathrm{NaBH}_{4}$, and are highly effective for the absorption and detoxification of many environmental contaminants. It was found that the particle surfaces consisted of a disordered $\mathrm{FeO}_{\mathrm{x}}$ species surrounding a polycrystalline core of $\mathrm{Fe}$ nanoparticles (Fig. 2(a,c)). To enhance their effectiveness, the nZVI particles were also impregnated with $\mathrm{Pd}$, and, contrary to expectations, the dopant metal was not found on the particle surface. Instead the Pd traversed the outer oxide layer in order to interact with the interior Fe nanoparticles, forming a Pd-rich interfacial layer between the $\mathrm{Fe}$ core and $\mathrm{FeO}_{\mathrm{x}}$ shell. 


\section{References}

1. M. Watanabe, D. W. Ackland, A. Burrows, C. J. Kiely, D. B. Williams, O. L. Krivanek, N.

Dellby, M. F. Murfitt, and Z. Szilagyi, Microsc. \& Microanal., 12 (2006) 515.

2. M. G. Burke, M. Watanabe, D. B. Williams, J. Hyde, J. Mater. Sci., 41 (2006) 4512.

3. P. G. Kotula, M. R. Keenan, J. R. Micheal, Microsc. \& Microanal., 9 (2003) 1.

4. A. Herzing, J. K. Edwards, A. F. Carley, G. J. Hutchings, C. J. Kiely, Chem. of Mat., in press.

5. W. Zhang, J. Nanopart. Res., 5 (2003) 323.
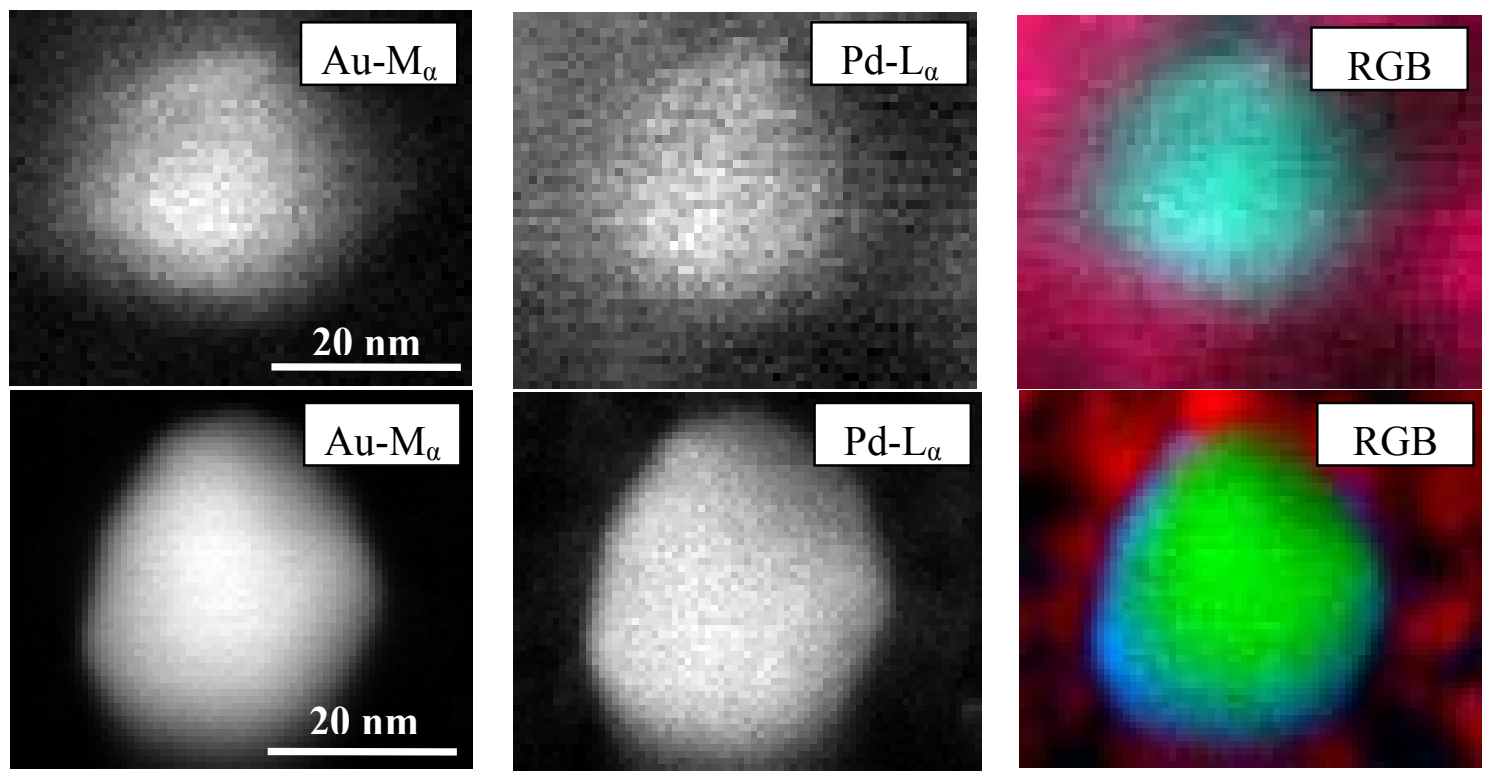

Figure 1 - Comparison of $\mathrm{Au}$ (green) and $\mathrm{Pd}$ (blue) elemental distributions in bi-metallic catalyst particles supported on $\mathrm{Al}_{2} \mathrm{O}_{3}$. The as-synthesized catalyst contains homogeneous $\mathrm{Au}-\mathrm{Pd}$ particles (top) while the particle surfaces become enriched with Pd after calcination at $400{ }^{\circ} \mathrm{C}$ (bottom).
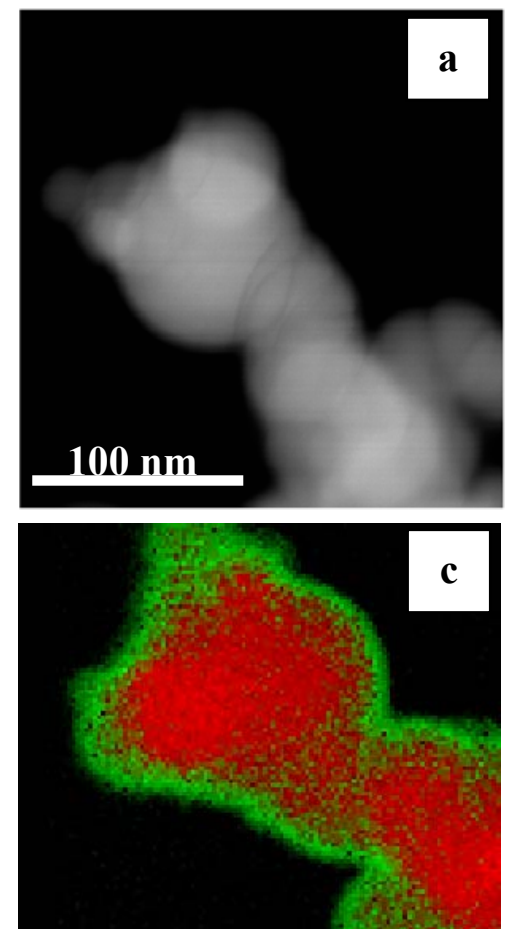

Figure 2 - ADF images of nZVI particles (a) as synthesized and (b) after impregnation with 1.5wt.\% Pd. RGB reconstructions of STEM-XEDS spectrum image data after PCA processing shows an $\mathrm{FeO}_{\mathrm{x}}$ surface layer (green) surrounding an Fe core (red) in the as-synthesized particles (c). Upon impregnation (d), the $\mathrm{Pd}$ traverses the oxide layer to react preferentially with the internal $\mathrm{Fe}$, forming a highly Pd-rich layer at the $\mathrm{Fe} / \mathrm{FeO}_{\mathrm{x}}$ interface (blue). 